\title{
No cotidiano das creches o cuidar e o educar caminham juntos
}

\author{
Cristiane Ribeiro da Silva \\ Maria Augusta Bolsanello \\ Universidade Federal do Paraná
}

\begin{abstract}
Resumo
O presente artigo contribui para o debate da dicotomia existente entre o cuidar e o educar que ainda vigora nas concepções de profissionais que atuam na creche. Enfatiza o cuidar e o educar como dimensões essenciais ao desenvolvimento de crianças de zero a seis anos de idade, exigindo um trabalho de forma planejada, com organização de espaços adequados, no sentido de estimular os processos de desenvolvimento infantil (motor, cognitivo, emocional, social). Salienta que a creche deve se configurar como lugar de interação e socialização de crianças, complementar à ação familiar, bem como ressalta a importância da formação do profissional que nela atua.

Palavras-chave: educação infantil; desenvolvimento infantil; formação de profissionais.
\end{abstract}

\begin{abstract}
In the everyday life of a crèche, care providing and educating go hand in hand

This article contributes towards the debate about the dichotomy between care providing and educating that continues to reign in the in the conceptions of nursery school professionals. The article emphasizes care provision and educating as being essential dimensions to the development of children from zero to six years of age. Thus, it is required that this work should be done in a planned manner, including the organization of adequate environments to stimulate the child development processes (motor, cognitive, emotional, social). The article emphasizes that a crèche must be a place where children can interact and socialize, complementing family activities. It also underlines the importance of the training received by professional staff who work in crèches.

Keywords: child education, child development, professional training.
\end{abstract}

O debate sobre a educação infantil encontra unanimidade ao considerar os aspectos do cuidar e do educar como dimensões essenciais ao desenvolvimento de crianças pequenas, o que tem gerado uma gama de pesquisas voltadas ao desenvolvimento humano, sobretudo o infantil, como bem apontam os estudos de Souza e Kramer (1992), Oliveira e Rossetti-Ferreira (1993), Machado (1994), Souza (1996), Oliveira (2000), Felipe (2001), entre outros. Afirma Seber (1997) que, ao contrário do que se pensava, o bebê não é uma "tábula rasa", mas é um sujeito que se constitui na interação com o meio. Graças às investigações sobre o bebê, ocorridas nas últimas décadas, como os estudos feitos por Brazelton e Cramer (1992), Klaus e Kennell (1992), Relier (1994) entre outros, foi possível afastar antigas concepções que levavam a supor que as crianças menores eram seres passivos, desprovidos de qualquer competência. Segundo Palácios (1995), as crianças não ficam apenas alternando vários períodos de sono sem a possibilidade de sua percepção estar em pleno dinamismo, e "hoje sabemos que é certo que as crianças menores passam muitas horas dormindo, mas que é certo também que seu mundo perceptivocognitivo é rico, complexo e ordenado, por mais que diste ainda das características que terá alguns meses depois" (Palácios, 1995, p. 42).

Portanto, compreender que os processos cognitivos iniciam-se desde o nascimento significa inferir que, ao longo da vida, esses processos tenderão a ficar mais aguçados, e para isso contribui, em grande parte, a interação social aliada a adequados cuidados pessoais (como alimentação, vestuário, proteção).

Dessa forma, as crianças pequenas necessitam de toda infra-estrutura possível que possa favorecer o seu desenvolvimento, estejam elas inseridas em contextos de instituições educativas ou não.

Felipe (2001, p. 27) lembra que Piaget, Vygotsky e Wallon tentaram mostrar que a capacidade de conhecer e aprender se constrói a partir das trocas estabelecidas entre o sujeito e o meio, concebendo o desenvolvimento infantil como um processo dinâmico, onde as crianças não são passivas e nem meras receptoras de informações que estão à sua volta. A autora lembra que "a articulação entre diferentes níveis de desenvolvimento (motor, afetivo e cognitivo) não se dá de forma isolada, mas sim, de forma simultânea e integrada."

São essas implicações que os profissionais que atuam em creches precisam considerar, ou seja, que 
seu trabalho cotidiano deve ocorrer tomando por base os processos de desenvolvimento próprios e dinâmicos dos infantes. Reforçar a formação dos profissionais de educação infantil pela apreensão das descobertas mais recentes em relação às crianças pequenas, é crucial. Isso, sem mencionar a necessidade de organizar adequadamente os espaços nas instituições educativas, os quais terão que, obviamente, respeitar e oportunizar o processo de desenvolvimento dos pequenos.

\section{A criança entre o cuidar e o educar}

O trabalho com crianças de zero a seis anos pressupõe o cuidado e a educação como intrínsecos à relação cotidiana. De um lado, as crianças necessitam dos cuidados essenciais ligados às questões de alimentação, vestuário, saúde, pelos quais todos os seres humanos são subjugados. De outro, necessitam também da interferência imediata, em especial do adulto, para a realização destes cuidados e outras tarefas do dia-a-dia. Essa interferência ocorrerá com maior ou menor intensidade à medida que o grau de autonomia (maturação física, emocional, afetiva) for se ampliando. Fica evidenciado que as atividades ligadas estritamente ao ato do cuidado são de extrema importância e que este ato não pode pretender-se desvinculado do processo de desenvolvimento, embora esta desvinculação tenha prevalecido (e ainda prevaleça) na concepção de atendimento às crianças em muitas creches e escolas de educação infantil, por décadas, em muitos países. Isso deve-se sobretudo ao fato de que, historicamente, a função das creches esteve associada à caridade, e essa visão foi por muito tempo reforçada pela Igreja e incentivada pela sociedade, de modo geral. Oliveira, Vitória e Ferreira (1992) afirmam que no Brasil, por exemplo, ... até o início deste século, o atendimento de crianças em creches não se distinguia do atendimento em asilos e internatos. Destinava-se basicamente a filhos de mães solteiras que não tinham condições de ficar com eles e criá-los. Isso gerava naquelas mulheres sentimento de pecado ou de culpa, e o atendimento institucional a seus filhos era considerado um favor, uma caridade ( $\mathrm{p}$. 18).

Essa concepção ampliou-se e, em face da crescente industrialização e da vinda dos imigrantes para o trabalho nas fábricas, as creches se tornaram exigências sociais cada vez maiores. E, dependentes de recursos alheios e com uma política de atendimento voltada às crianças pobres, a ênfase à maneira assistencial de realizar o acolhimento infantil foi inevitável, como ainda apontam Oliveira e cols. (1992). Estas autoras enfatizam que as entidades filantrópicas eram as responsáveis pelas poucas creches que existiam fora das indústrias nas décadas de 30-50, recebendo donativos de famílias ricas e alguma ajuda governamental. Eram os médicos e sanitaristas da época quem defendiam a existência da creche, preocupados com as condições de vida das crianças pobres, vítimas frequientes de infecções, desnutrição e maltratos.

Portanto, evidencia-se que o modo de atendimento atual das creches descende da visão assistencialista assinalada. Porém, a partir dos avanços já ocorridos em relação ao atendimento de crianças, advindos de novas formas de concepção do desenvolvimento infantil e também de mudanças estruturais (econômicas, sociais, tecnológicas) ocorridas em nível mundial, e com ênfase na realidade brasileira, remetese aos adultos uma responsabilidade sem igual na promoção dos direitos das crianças pequenas de forma integral, se tornando inclusive uma responsabilidade social.

Aliada às questões da sobrevivência, vislumbra-se a necessidade intrínseca de a criança interagir, aprender, sentir, perceber, ou seja, quando o adulto realiza ações sobre a criança do ponto de vista do cuidar, ao mesmo tempo estabelece com ela uma vasta gama de relações. Essas ações do adulto (sejam por meio do tato, do segurar, do manusear, da linguagem) contribuem para o aprimoramento tanto das aquisições cognitivas quanto das interações e experiências individuais e coletivas infantis (Flavell, Miller \& Miller, 1999).

É preciso ressaltar que as relações que as crianças tecem não ocorrem sempre da mesma forma com todas elas e nem ao mesmo tempo. Essa teia de relações faz que a criança passe por momentos de desequilíbrio diante de algumas situações que a obrigam a modificar seu comportamento, como afirmam Oliveira e cols. (1992). Segundo as autoras, isso acontece porque a criança nasce com certas estruturas internas que se modificam na interação com o ambiente, que geralmente está repleto de novidades a serem descobertas. É enfrentando novos objetos e novas experiências que a criança constrói novas formas de apreendê-los, modificando-se em um processo contínuo de reorganização.

Por conseguinte, entende-se que as unidades de educação infantil devem ir mais além da função de "guarda e cuidado", ou seja, devem realizar um trabalho de forma planejada, organizando espaços adequados no sentido de estimular o processo de desenvolvimento (motor, cognitivo, emocional, social) das crianças. Cabe ressaltar, porém, que a instituição educativa não substitui a ação da família. Pelo contrário, se configura como um lugar de interação e socialização das crianças, complementar à 
ação familiar e que por isso, necessita de uma relação de confiança e de responsabilidade entre ambas.

\section{Profissionais da educação infantil: uma formação a caminho!}

Muito se discute em relação à formação de profissionais que atuam com crianças pequenas, na medida em que há premência em integrar a educação e o cuidado, e se depara com um contexto precário de formação e um grande contingente de leigos, como bem salienta Kishimoto (1999, p. 61). A própria observação do contexto da educação infantil na atualidade aponta para a necessidade de se investir intensamente na formação destes profissionais. Como bem enfatizam Mantovani e Bondioli (1998), o profissional de creche deve possuir uma consistente formação acerca do processo de desenvolvimento da criança, a fim de que possa selecionar e empreender atividades em função deste desenvolvimento. Para estas autoras, uma tarefa essencial deste profissional é a de especificar os modos e os objetivos de uma programação que leve em conta uma visão integradora do desenvolvimento infantil. Salientam ainda que a criança adquire a consciência dos outros e de si mesma por meio de seu corpo, pela maneira como é tocada e entra em contato com os outros corpos, pela maneira como é contida, limpa, cuidada, tranqüilizada, pelo modo como pode expressar-se. Por estes motivos, a formação do profissional de creche é, sem dúvida alguma, temática de extrema urgência e importância, uma vez que sua atuação interfere diretamente na formação biopsicossocial dos pequenos com os quais atua.

Oliveira e cols. (1992, p. 123) enfatizam a importância da figura do educador de creche, afirmando que é "ele que deverá ser a constante recriação da proposta pedagógica da creche, criando um suporte afetivo básico e cuidando para que a frágil estruturação do coletivo infantil não ameace seus integrantes". Consideram o educador como elemento chave que deve ser adequadamente selecionado e treinado, uma vez que deve ser o irradiador, o mediador verbal do grupo, o organizador do espaço e do tempo das atividades, o colocador de limites, o apoiador afetivo de inúmeras ocasiões.

Portanto, o desafio colocado tanto para os professores quanto para os gestores e dirigentes é o de possiblitar uma organização da creche que oportunize ao máximo as experiências sociais, afetivas, cognitivas e outras das crianças, por meio de diretrizes pedagógicas condizentes com essas experiências. Além do mais, a utilização de instrumentos teóricos e técnicos deverá fazer parte desse contexto, para auxiliar os profissionais na elaboração de práticas psicopedagógicas que respeitem as crianças pequenas. E nesse particular, estes profissionais de educação infantil precisam lançar mão das inúmeras contribuições teóricas para sustentação de sua prática. Mas, ao mesmo tempo, precisam deter também a condição de reflexão tanto do ponto de vista teórico quanto do que diz respeito às praticas por eles adotadas. Felipe (2001) alerta sobre a necessidade de se considerar que as teorias científicas podem sofrer reformulações com o passar do tempo, e portanto, não devem ser entendidas como verdades definitivas, mas sim, passíveis de questionamentos, sujeitas a transformações.

Nesse aspecto, a formação de profissionais para a educação infantil precisa se tornar reflexiva, ou seja, deve possibilitar ao educador compreender a dimensão educativa do seu trabalho e construir autonomia intelectual para refletir sobre as práticas psicopedagógicas que exerce. Assim, essa formação não ocorre instantaneamente, mas por meio de um caminho longo a ser percorrido e a ser construído, que precisa de investimento de tempo e de recursos suficientes a essa construção.

Campos (1999) afirma que determinados aspectos podem contribuir com a formação dos profissionais de creche, e assinala alguns que dizem respeito ao perfil do educador para a educação infantil, tais como a necessidade de: a) uma formação permanente que alimente a prática docente, permitindo o confronto do conhecimento teórico com a real situação vivida com as crianças; b) uma estrutura de apoio na instituição, que dê condições aos profissionais para lidarem com o estresse, prevendo momentos de descanso e rodízio de funções; c) interação com vários "outros" e não só com o aluno, incluindo o desempenho de seu papel na dinâmica da equipe de trabalho, em seu relacionamento com as famílias e os profissionais de outras agências educativas e sociais; d) aprender a refletir sobre sua prática, construindo um projeto educativo próprio, utilizando a documentação, a avaliação, a pesquisa e a observação.

Esses aspectos, segundo o autor citado, podem contribuir para uma concepção de formação de educadores para a educação infantil, tendo como referência primordial a especificidade do atendimento de crianças de zero a seis anos.

\section{A organização do trabalho psicopedagógico na creche}

A organização do trabalho psicopedagógico para crianças pequenas é um outro aspecto a ser considerado no cotidiano cuidar/educar das creches, pois é a partir da organização assumida pela 
instituição que consiste a materialização do atendimento das crianças.

Barbosa e Horn (2001) indicam que o cotidiano da creche tem de prever momentos diferenciados dos fornecidos para crianças maiores. Salientam que vários tipos de atividades devem envolver a jornada diária dos infantes, como o horário da chegada, a alimentação, a higiene, o repouso, as brincadeiras, os jogos diversificados (como o de faz-de-conta, os jogos imitativos e motores), a exploração de materiais gráfico e plástico (os livros de histórias, as atividades coordenadas pelo adulto) e outros. Essas autoras advertem que as atividades (sejam elas realizadas em espaços abertos ou fechados) devem sempre permitir experiências múltiplas que estimulem a criatividade, a experimentação, a imaginação, estimulando as distintas linguagens expressivas e incentivando a interação social.

Entende-se que a organização da creche deve partir das necessidades de desenvolvimento e das diferenças individuais apresentadas pelas crianças e não ao contrário, ou seja, a adaptação pura e simples da criança à organização, imposta face ao argumento do "sempre foi assim e funcionou"!

Para que a estruturação espaço-temporal tenha significado, Barbosa e Horn (2001) acreditam ser de fundamental importância o educador conhecer como as crianças brincam, como estas brincadeiras se desenvolvem, o que mais gostam de fazer, em que espaços preferem ficar, o que lhes chama mais a atenção, em que momentos do dia estão mais tranquiilas ou mais agitadas. Isso envolve partir da especificidade, em um processo avaliativo do repertório de cada criança.

Organizar o trabalho psicopedagógico na creche inclui tanto a organização física como as condições para a realização das atividades a serem desenvolvidas com as crianças. Contudo, observa-se em muitos casos a visão assistencialista aliada à desculpa da "contenção de despesas", que comumente resultam em construções projetadas inadequadamente (escadas escorregadias, banheiros próximos a cozinhas, salas muito pequenas, sem refeitório, poucos espaços para lazer) que não incentivam nem profissionais nem crianças a se sentirem confortáveis no local. Por isso, a arquitetura da creche não é um pequeno detalhe. É antes a materialização do atendimento necessário às crianças de zero a seis anos em instituições educativas, e que por isso precisa ser bem planejada e organizada. Souza (1996, p. 66) chama atenção para o fato de que espaço físico, proposta pedagógica e atenção às necessidades básicas infantis não podem ser pensados isoladamente, devendo o "ambiente propiciar a integração criança-espaço físico, favorecendo possibilidades de opções de atividades, livre circulação nas dependências internas e externas, independência no uso do equipamento e alternativas de experiência."

Além disso, há de se considerar a qualidade dos materiais utilizados para a construção da creche e também dos materiais pedagógicos, dos utensílios de cozinha e de outros equipamentos, estejam eles na sala de aula, berçário, banheiros, parquinho e outros. Essa consideração pode parecer desnecessária, na medida em que existem parâmetros técnicos para a sua análise, mas nunca é demais lembrá-los. Como muitas creches não apresentam condições adequadas de atendimento, mesmo creches com pouco tempo de existência, então é evidente que mesmo sendo óbvia a necessidade de padrões de qualidade técnica, estes não são implementados e vistoriados a contento.

Além do cuidado com a construção arquitetônica, outros elementos definem a organização do trabalho psicopedagógico. Um desses elementos diz respeito à formação dos diferentes profissionais que atuam nas creches. Em relação aos professores, consideram-se os argumentos expostos anteriormente. Mas analisando os outros profissionais que atuam em outros espaços como na direção, coordenação, cozinha, lactário, limpeza, é necessário também visualizá-los como alvo de formação e capacitação permanente. É crucial, não só aos professores mas também aos outros profissionais envolvidos no atendimento à criança, a percepção da importância do trabalho que realizam na creche. Um exemplo disso pode ser identificado no preparo dos alimentos. Além de conter as indicações fornecidas pelos especialistas da área, existe também o profissional que realiza a ação. Esse profissional tem uma história, um nome, uma vivência, que poderão contribuir com a forma mais desejável de atendimento às crianças, se a ele for dispensada atenção e consideração. Dessa forma, cozinhar ganha significado. Cozinhar para quem, por quê e para quê? Indagações e tarefas sem sentido, "desmobilizadoras", passam a ter significado, a fazer parte do estar na creche com crianças que se beneficiarão não apenas da alimentação com seus nutrientes, proteínas, vitaminas, mas também das atitudes provindas daquela ação respeitosa para com as crianças, os colegas e os pais. Assim, determinados aspectos que fazem parte do cotidiano da creche podem influenciar sobremaneira no desenvolvimento infantil. Mas como bem salienta Felipe (2001, p. 32), "muitas vezes estes aspectos, tais como a adaptação à escola, alimentação, a troca de fraldas, os momentos de sono, entre outros, passam desapercebidos ou se constituem em práticas pouco discutidas no dia-a-dia das pessoas que lidam diretamente com a educação de crianças pequenas." 
Portanto, o papel do profissional de creche precisa ser valorizado, necessitando de formação e qualificação continuada. Não se deve esquecer também que, quanto melhores condições salariais e de trabalho os profissionais tiverem, tanto maior o seu comprometimento com a qualidade de atendimento na creche.

Um outro aspecto que pode contribuir para um comprometimento com a qualidade do atendimento infantil se refere às formas menos burocráticas de administração das creches, que permitam trabalhar no sentido de uma gestão colegiada, democrática, proporcionando aos profissionais a inserção em uma dinâmica que seja capaz de estimular, instigar e envolver o pensar e o agir sobre a infância. Enfim, a necessidade de um trabalho coletivo, interdisciplinar, onde inclusive se faz necessária a presença do psicólogo escolar, cujo papel específico, segundo Bentes (1996), seria o de ser o elo de ligação entre os vários profissionais da equipe, estimulando a reciprocidade e aproximando as parcerias. Além disso, proporcionar também aos pais uma relação de confiança mútua pode ser um dos aspectos enriquecedores do desenvolvimento das crianças envolvidas no cotidiano da creche.

\section{Cuidar e educar são de responsabilidade social!}

A complexa prática do trabalho realizado em creche não permite uma conclusão única. Aliás, a tentativa de reflexão sobre o cotidiano de creches não poderá se esgotar e nem é essa a pretensão do presente artigo. Pelo contrário, é pensando sobre o que já foi dito, escrito, pesquisado, como bem corroboram os estudos, entre outros, de Oliveira (1992); Rosemberg e Campos (1994); Kramer (1994); Sândalo (1995); Nalini (1996); Kishimoto (1999); Ostetto (2000); Hoffmann e Silva (2001); Rosseti-Ferreira, Mello, Vittoria, Gosuen e Chaguri ( 2001), e sobre o que ainda será dito, escrito, pesquisado, que ocorre essa reflexão. Mas, o ponto em comum que será sempre necessário retomar diz respeito às contribuições que auxiliem na melhoria do atendimento de crianças de zero a seis anos de idade.

Bujes (2001) afirma que as crianças participam das permanentes transformações dos contextos culturais e históricos em que vivem, sendo também transformadas pelas experiências que adquirem neste mundo extremamente dinâmico. Para a autora, é necessário dar-se conta de que estas experiências são muito relevantes para elas e que algumas jamais se repetirão, surgindo então a necessidade de se defender o direito da criança à infância, o que tem sido muitas vezes negado a muitas delas.
Nesse aspecto, é responsabilidade de toda a sociedade a promoção do acesso da infância à educação e ao cuidado, com políticas que respeitem os direitos fundamentais da criança, mantendo firmes os critérios de qualidade para o seu atendimento biopsicossocial. Negar um atendimento de qualidade à infância é desconsiderar toda a gama de conhecimentos produzidos pela cultura humana em favor das crianças pequenas, que quando nascem para os pais, nascem também para uma sociedade, a qual terão que apreender e nela interferir.

Concluindo, organizar a creche significa adequar o tempo e o espaço a esse atendimento, numa perspectiva psicopedagógica, considerando os aspectos do cuidar e do educar como dimensões essenciais ao desenvolvimento de crianças pequenas, de modo que profissionais e crianças aprendam a conviver e a viver face à multiplicidade de interferências do cotidiano, sem deixar de lado, ao mesmo tempo, a importância de realizar ações articuladas com outros setores da sociedade igualmente responsáveis por esse espaço educativo.

\section{Referências}

Barbosa, C. S. \& Horn, M. G. S. (2001). Organização do espaço e do tempo na escola infantil. Em M. Craidy e G. Kaercher (Org.), Educação infantil: pra que te quero? (p. 67-79). Porto Alegre: Artmed.

Bentes, N. O. (1996). Atuação do psicólogo escolar na equipe interdisciplinar. Dissertação de Mestrado não publicada, Universidade de São Paulo.

Brazelton, T. B. \& Cramer, B. G. (1992). As primeiras relações. São Paulo: Martins Fontes.

Bujes, M. I. E. (2001). Escola infantil: pra que te quero? Em M. Craidy e G. Kaercher (Org.), Educação infantil: pra que te quero? (p. 13-22). Porto Alegre: Artmed.

Campos, M. M. (1999). A formação de professores para crianças de 0 a 10 anos: modelos em debate. Em Educação \& Sociedade: formação de profissionais da educação: políticas e tendências. Revista quadrimestral de Ciência da Educação / CEDES n. 69.

Felipe, J. (2001). O desenvolvimento infantil na perspectiva sociointeracionista: Piaget, Vygotsky, Wallon. Em M. Craidy e G. Kaercher (Org.), Educação infantil: pra que te quero? (p. 61-66). Porto Alegre: Artmed.

Flavell, J. H.; Miller, P. H. \& Miller, S. A. (1999). Desenvolvimento cognitivo. ( $3^{\mathrm{a}} \mathrm{ed}$.) Porto Alegre: Artmed.

Hoffmann, J. \& Silva, M. B. G. (2001). Ação educativa na creche ( $3^{\mathrm{a}}$ ed.). Porto Alegre: Meditação.

Kishimoto, T. M. (1999). Política de formação profissional dos professores da educação infantil: Pedagogia e Normal Superior. Educação \& Sociedade: formação de profissionais da educação: políticas e tendência, 68, 61-79.

Klaus, M. H. \& Kennell, J. H. (1992). Pais/bebê: a formação do apego. Porto Alegre: Artes Médicas.

Kramer, S. (1994). Currículo de educação infantil e a formação dos profissionais de creche e pré-escola: questões teóricas e polêmicas. Em Brasil, Ministério da Educação e do Desporto. Secretaria da Educação Fundamental. Coordenação Geral de 
Educação Infantil. Por uma política de formação do profissional de educação infantil. Brasília: MEC.

Machado, M. L. (1994). Educação infantil e sociointeracionismo. Em Z. M. R. Oliveira (Org.), Educação infantil: Muitos olhares (p. 25-50). São Paulo: Cortez.

Mantovani, S. \& Bondioli, A. (1998). Manual de educação infantil: de 0 a 3 anos: uma abordagem reflexiva. ( $9^{\mathrm{a}}$ ed.) Porto Alegre: Artmed.

Nalini, D. (1996). Reflexões sobre a construção de um marco educativo para a creche. Dissertação de Mestrado. Universidade Estadual de São Paulo.

Oliveira, Z. M. R. (2000). A criança e seu desenvolvimento: perspectivas para se discutir a educação infantil. São Paulo: Cortez.

Oliveira, Z. M. R.; Vitoria, T. \& Ferreira, M. C. R. (1992). Crianças, creche, faz de conta \& cia. Petrópolis: Vozes.

Oliveira, Z. M. R. \& Rosseti-Ferreira, M. C. (1993). O valor da interação criança-criança em creches no desenvolvimento infantil. Cadernos de Pesquisa, 87, 62-70.

Ostetto, L.E. (2000). Encontros e encantamentos na educação infantil. Campinas: Papirus.

Palácios, J. (1995). Processos cognitivos básicos na primeira infância. Em C. Coll; J. Palácios e A. Marchesi (Org.), Desenvolvimento psicológico e educação: psicologia evolutiva, 1, 42-54, Porto Alegre: Artmed.

Relier, J. P. (1994). Importance de la relation mère-enfant avant la naissance. Em A. Blindt-Morris; F. Garnier \& M. Glaumaud (Orgs), Le petit enfant et l'éveil culturel: rôles des familles, rôle des institutions (p. 23-33). Paris: Syros.

Rosemberg, F. \& Campos, M. M. (1994). Creches e pré-escolas no Hemisfério Norte. São Paulo: Cortez.

Rossetti-Ferreira, M.C.; Mello, A.M.; Vittoria, T.; Gosuen, A. \& Chaguri, A.C. (2001). Os fazeres na educação infantil. ( $3^{\mathrm{a}} \mathrm{ed}$.) São Paulo: Cortez.

Sândalo, J. A. (1995). Creche pública como espaço socioeducativo: um relato de experiência. Dissertação de Mestrado não publicada, Faculdade de Educação da Universidade Estadual de São Paulo.

Seber, M. G. (1997). Psicologia do pré-escolar: uma visão construtivista. São Paulo: Moderna.

Souza, A. M. C. (1996). Educação infantil: uma proposta de gestão municipal. ( $2^{\mathrm{a}}$ ed.) Campinas: Papirus.

Souza, S. J. \& Kramer, S. (1992). O debate Piaget/Vygotsky e as políticas educacionais. Cadernos de Pesquisa, 77, 69-81. 
Sobre as autoras

Cristiane Ribeiro da Silva: Assessora técnico-pedagógica do Centro de Estudos e Pesquisas em Educação (UFPR) Mestranda em Educação (UFPR).

Maria Augusta Bolsanello: Professora de Graduação e Pós-graduação do Setor de Educação da UFPR. Endereço para correspondência: Rua Padre Oswaldo Gomes, 104 Guabirotuba 81510-100 - Curitiba, PR. Fone/fax: (41) 2966115. E-mail: abolsanello@hotmail.com. 